\title{
Doodling in the margins
}

\author{
Ashish S. Shah, MD

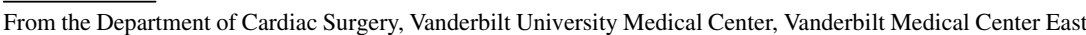 \\ Nashville, Tenn. \\ Disclosures: Author has nothing to disclose with regard to commercial support. \\ Received for publication Nov 15, 2017; accepted for publication Nov 15, 2017; available ahead of print Dec 9, \\ 2017. \\ Address for reprints, Ashish S. Shah, MD, Department of Cardiac Surgery, Vanderbilt University Medical Center, \\ Vanderbilt Medical Center East, 1215 21st Ave S, Suite 5025, Nashville, TN 37232 (E-mail: ashish.s.shah@ \\ vanderbilt.edu). \\ J Thorac Cardiovasc Surg 2018;155:e153 \\ $0022-5223 / \$ 36.00$ \\ Copyright (C 2017 by The American Association for Thoracic Surgery \\ https://doi.org/10.1016/j.jtcvs.2017.11.056
}

In this issue of the Journal, Sultan and colleagues ${ }^{1}$ from the University of Pittsburgh have presented a laudable case report on adding an expeditious aortic valve replacement to an unusable donor heart, rendering it usable. This approach to "marginal" organs remains firmly in the world of anecdote. Although case reports like this are meant to encourage the use of such hearts and thus increase the numbers of possible donors, such one-off reports will have no real significance on a national level. Certainly, such heroics are vital and impactful to the individual patient. As Sultan and colleagues ${ }^{1}$ point out, there is a body of literature that supports doing surgical procedures on donor hearts. It will be interesting to see if there is role for rapid-deployment valves in this setting. We will also need to consider the long-term consequences of a bioprosthesis in an immunocompromised patient.

Although Sultan and colleagues ${ }^{1}$ are to be commended for boldly expanding the donor pool, we are still left with the eternal problem of substantially increasing available donors. Fixing valve problems will not be enough. Moreover, there is an inconvenient truth about regulatory pressures and risk. What program really wants to take on these types of donors when there is no allowance by Medicare or the

\section{Reference} e151-2.

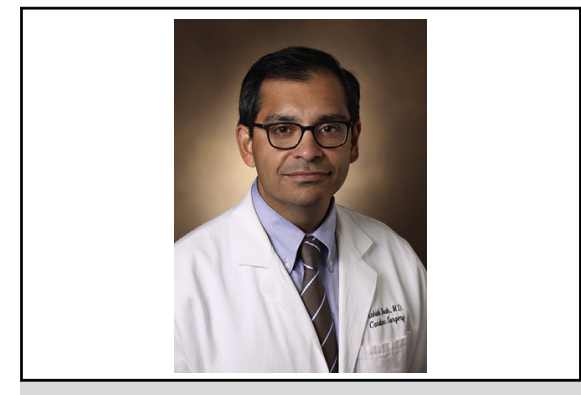

Ashish S. Shah, MD

Central Message

Sultan and colleagues present an innovative surgical approach, but the report also reveals vulnerabilities in the field.

See Article page e151.

United Network for Organ Sharing for taking on a highrisk donor? We certainly do not get extra credit or an adjustment in our expected outcomes. Only large programs have the ability to do such things consistently without jeopardizing their publicly reported results. The generalizability of the technique and strategy is thus limited, amounting to doodling in the margins of a broader, more complex document. After 50 years of human heart transplantation, our patients deserve more than doodling.

1. Sultan I, Seese L, Lagazzi L, Gleason TG. Concomitant aortic valve replacemen with orthotopic heart transplantation. J Thorac Cardiovasc Surg. 2018;155: 